\title{
Mindfulness: Cognitive and Emotional Change
}

\section{Hossein Kaviani}

School of Psychology, Faculty of Creative Art, Technologies \& Science, University of Bedfordshire, Luton, UK

*Corresponding author: Hossein Kaviani, School of Psychology, Faculty of Creative Art, Technologies \& Science, University of Bedfordshire, Luton, LU1 3JU, UK, Tel: +44-1582743765; E-mail : Hossein.Kaviani@beds.ac.uk

Received date: December 22, 2016; Accepted date: December 22, 2016; Published date: December 28, 2016

Copyright: ( 2016 Kaviani $\mathrm{H}$. This is an open-access article distributed under the terms of the Creative Commons Attribution License, which permits unrestricted use, distribution, and reproduction in any medium, provided the original author and source are credited.

\section{Editorial}

Beck [1] developed cognitive therapy which led to broad therapeutic innovations and successful applications in the field of psychotherapy [2-4]. Mostly, by virtue of its linear nature and lack of empirical support from cognitive science, this clinically-driven model faced some limitations in practice [5]. To overcome the shortcomings, Teasdale and Barnard [6] experimentally investigated the link between cognition and emotion and came up with a non-linear/multilayer model (a science-driven model). As they suggested, information are processed in cognitive system at two qualitatively distinct levels, namely propositional level and implicational level. The former is linked with specific meanings behind language constructs (or words); the latter is associated with generic meanings behind language constructs (or words). In Beckian approach, it is the specific meanings that result in emotion production, whilst in the non-linear/multilayer model of cognition, in order to elicit emotional response, the generic, holistic meanings should be processed at implicational level [7].

Furthermore, Teasdale and Barnard [6] explain that generic, emotion-eliciting meanings cannot simply communicate through words. For this to happen, they surmised that other factors such paralanguage parameters (words tone, rhythm, composition, etc.) have to come into play. Apart from this, they also suggest that the physiological and bodily sensations which are felt during emotional experiences are processed within the implicational level. There seems to have been this reason, among others, that Teasdale et al. [8] adopted some elements of mindfulness-based stress reduction (MBSR; developed by Jon Kabat-Zinn) and combined them with cognitivebehavioural therapy (CBT) techniques which was coined as mindfulness-based cognitive behaviour therapy (MBCT) [9].

Mindfulness meditations (body scanning, breath meditation, sitting meditation, walking meditation, yoga, and the like) would enhance a non-judgmental worldview and an ability for "being in the present moment" [9]. In this eight-weekly group training program, clients are involved in different in-session activities and home works which help them see thoughts and feelings as ongoing events in the mind and not actual incidents in the real outer world. In fact, by MBCT training, a grounding basis will be provided on which the person learns how to disengages themselves from unhelpful thoughts and related feelings, and simply "observes" instead of "getting lost" in ruminations, worries, and negative cognitive experiences [8]. This allows the individual to bring their attention back to the present moment that, in turn, facilitates "acceptance". One explanation for this is that being aware of the present moment and fully attentive to its thorough qualities would prepare the ground for one to be in a lucid contact with moment-bymoment 'richness' of the reality, which would, in turn, result in an enhanced well-being [10].
After testing the effectiveness of MBCT in some randomized clinical trials, Segal et al. [8] employed this therapy intervention to prevent relapse (based on a model of cognitive vulnerability to depressive relapse) [11-14] in those who suffered from recurrent major depression. They showed that decline in relapse rate in patients receiving $\mathrm{MBCT}$ training was more than $50 \%$. Using $\mathrm{MBCT}$ along with antidepressants gives rise to less relapse over a 15-months follow-up $[15,16]$.

Moreover, MBCT proved to be effective to reduce excessive worry or anxiety symptoms, sleep problems and enhance quality of life in both physical and psychological domains [16-18]. Moreover, empirical findings provide further evidence showing that MBCT is a useful intervention for enhancing well-being in non-clinical groups of people (e.g., university students, fire fighters, stage performers and the like) who are naturally exposed to real life stressful situations in which they experience high levels of anxiety and depression $[19,20]$. The results depict a picture showing that MBCT can be effective at relieving exam related anxiety and dysphoria, and enhancing quality of life in nonclinical groups as well as sub-clinically depressed individuals who may be susceptible to emotional disorders.

Underpinning cognitive mechanisms to explain such changes can be suggested. Negative, self-defeating, dysfunctional thoughts usually are thought to underpin depressive symptoms; which would potentially give rise to more negative thoughts. This vicious cycle is deemed as a source of vulnerability for relapse of depression. Research shows that mindfulness meditation training would have an improving impact on attention, executive functioning and emotion regulation [21-24]. In fact, mindfulness training package helps the trainee to gain more cognitive control over habitual unhelpful thinking pattern including rumination, worry and intrusive images [25]. To date, dozens of findings associated with this phenomenon have emerged. The evidence support a positive relationship between rumination and recall overgenerality in autobiographical memory in both normal and clinical samples [26-30]. Apart from this, research findings confirm that overgeneral retrieval in autobiographical memory is linked with poor social problem solving [31-36]. By this account, one can conclude that mindfulness plays a pivotal role in breaking the vicious cycle by improving specificity in memory retrieval and consequently reinforcing effective problem solving.

With all these in mind, mindfulness seems to have played a major part in the field of mental health over the past two decades and provided a crucial conjunct therapeutic component which has revolutionized modern models of psychotherapy. Although the widespread use of mindfulness in various therapies and for different disorders is an eye-catching phenomenon, still more research-based evidence is needed to gauge its specific effects and limitations. 
Page 2 of 2

\section{References}

1. Beck AT (1972) Depression: Causes and treatment. University of Pennsylvania Press.

2. Beck AT (1967) Depression: Clinical, experimental, and theoretical aspects. Harper \& Row, New York.

3. Beck AT, Rush AJ, Shaw BF, Emery G (1979) Cognitive therapy of depression. Guilford Press, New York.

4. Hollon SD, Shelton RC, Loosen PT (1991) Cognitive therapy and pharmacotherapy for depression. J Consult Clin Psychol 59: 88-99.

5. Teasdale JD (1996) The relationship between cognition and emotion: The mind-in-place in mood disorders. In: DM Clark, CG Fairburn (eds.), Science and practice of cognitive behaviour therapy. Oxford University Press, Oxford, UK. pp: 67-93.

6. Teasdale JD, Barnard PJ (1993) Affect, cognition, and change: remodelling depressive thought. Lawrence Erlbdum Associates, Hove.

7. Teasdale JD (1993) Emotion and two kinds of meaning: Cognitive therapy and cognitive science. Behav Res Ther 31: 339-354.

8. Segal ZV, Williams JMG, Teasdale JD (2002) Mindfulness-based cognitive therapy for depression: A new approach to preventing relapse. Guilford Press, New York.

9. Kabat-Zinn J (1990) Full catastrophe living: How to cope with stress, pain and illness using mindfulness meditation. Dell, New York.

10. Brown KW, Ryan RM (2003) The benefits of being present: Mindfulness and its role in psychological well-being. J Pers Soc Psychol 84: 822-848.

11. Teasdale JD, Segal ZV, Williams JMG, Ridgeway VA, Soulsby JM, et al. (2000) Prevention of relapse/recurrence in major depression by mindfulness-based cognitive therapy. J Consult Clin Psychol 68: 615-623.

12. Segal ZV, Williams JMG, Teasdale JD, Gemar M (1996) A cognitive science perspective on kindling and episode sensitization in recurrent affective disorder. Psychol Med 26: 371-380.

13. Teasdale JD, Segal Z, Williams JMG (1995) How does cognitive therapy prevent depressive relapse and why should attention control (mindfulness) training help? Behav Res Ther 33: 25-39.

14. Teasdale JD (1988) Cognitive vulnerability to persistent depression. Cogn Emot 2: 247-274.

15. Ma SH, Teasdale JD (2004) Mindfulness-based cognitive therapy for depression: Replication and exploration of differential relapse prevention effects. J Consult Clin Psychol 72: 31-40.

16. Kuyken W, Byford S, Taylor RS, Watkins E, Holden E, et al. (2008) Mindfulness-based cognitive therapy to prevent relapse in recurrent depression. J Consult Clin Psychol 76: 966-978.

17. Roemer L, Orsillo SM (2007) An open trial of an acceptance-based behavior therapy for generalized anxiety disorder. Behav Ther 38: 72-85.

18. Yook K, Lee S, Ryu M (2008) Usefulness of mindfulness-based cognitive therapy for treating insomnia in patients with anxiety disorders a pilot study. J Nerv Ment Dis 196: 501-503.

19. Kaviani H, Javaheri F, Hatami N (2011) Mindfulness-Based Cognitive Therapy (MBCT) reduces depression and anxiety induced by real stressful setting in non-clinical population. Int J Psychol Psychol Ther 11: 285-296.
20. Kaviani H, Hatami N, Javaheri F (2012) The impact of Mindfulness-based Cognitive Therapy (MBCT) on mental health and quality of life in a subclinically depressed population. Arch Psychiatr Psychother 1: 21-28.

21. Lutz A, Slagter HA, Dunne JD, Davidson RJ (2008) Attention regulation and monitoring in meditation. Trends Cogn Sci 12: 163-169.

22. Slagter HA, Lutz A, Greischar LL, Francis AD, Nieuwenhuis S, et al. (2007) Mental training affects distribution of limited brain resources. PLOS Biology 5: 1228-1235.

23. Tang YY, Ma YH, Wang J, Fan YX, Feng SG, et al. (2007) Short-term meditation training improves attention and self-regulation. Proc Natl Acad Sci USA 104: 17152-17156.

24. Nielsen L, Kaszniak AW (2006) Awareness of subtle emotional feelings: A comparison of long-term meditators and non-meditators. Emotion 6: 392-405.

25. Nolen-Hoeksema S (1991) Responses to depression and their effects on the duration of depressive episodes. J Abnorm Psychol 100: 569-582.

26. Watkins E, Teasdale JD (2001) Rumination and over general memory in depression: Effects of self-focus and analytic thinking. J Abnorm Psychol 110: 353-357.

27. Watkins ER, Teasdale JD (2004) Adaptive and maladaptive self-focus in depression. J Affect Disord 82: 1-8.

28. Watkins ER, Teasdale JD, Williams RM (2000) Decentering and distraction reduce over general autobiographical memory in depression. Psychol Med 30: 911-920.

29. Williams JMC (1996) Depression and the specificity of autobiographical memory. In: DC Rubin (Ed.), Remembering our past: Studies in autobiographical memory. Cambridge University Press, Cambridge, UK. pp: 244-267.

30. Ramponi C, Barnard P, Nimmo-Smith I (2004) Recollection deficits in dysphoric mood: An effect of schematic models and executive mode? Memory 12: 655-670.

31. Evans J, Williams JMG, O'Loughlin S, Howells K (1992) Autobiographical memory and problem solving strategies of parasuicide patients. Psychol Med 22: 399-405.

32. Goddard L, Dritschel B, Burton A (1996) Role of autobiographical memory in social problem-solving and depression. J Abnorm Psychol 105: 609-616.

33. Goddard L, Dritschel B, Burton A (1997) Social problem-solving and autobiographical memory in non-clinical depression. Br J Clin Psychol 36: 449-451.

34. Pollock LR, Williams JMG (2001) Effective problem solving in suicide attempters depends on specific autobiographical recall. Suicide Life Threat Behav 31: 386-396.

35. Kaviani H, Rahimi-Darabad P, Naghavi HR (2005) Autobiographical memory retrieval and problem-solving deficits of Iranian depressed patients attempting suicide. J Psychopathol Behav Assess 27: 39-44.

36. Kaviani H, Rahimi M, Rahimi-Darabad P, Naghavi HR (2011) Over general memory retrieval and ineffective problem-solving in depressed suicide-ideators: Implication for therapy. Int J Psychol Psychol Ther 11: 413-423. 